\title{
ATM Inhibitor M 3541
}

National Cancer Institute

\section{Source}

National Cancer Institute. ATM InhibitorM 3541. NCI Thesaurus. Code C138076.

An orally bioavailable inhibitor of ataxia telangiectasia mutated kinase (ATM), with potential chemo-/radio-sensitizing and antineoplastic activities. Upon oral administration, M 3541 targets and binds to AT M, thereby inhibiting the kinase activity of AT M and ATMmediated signaling. This prevents DNA damage checkpoint activation, disrupts DNA damage repair, induces tumor cell apoptosis, and leads to cell death of ATMoverexpressing tumor cells. In addition, M 3541 sensitizes tumor cells to chemo- and radiotherapy. AT M, a serine/threonine protein kinase, is upregulated in a variety of cancer cell types; it is activated in response to DNA damage and plays a key role in DNA-strand repair. 